\title{
Study on the Risk of Regional Energy Security Cooperation
}

\author{
Ying Shen, Xintong Yang, Xiaoli Guo* \\ Changchun University of Technology, Changchun, P.R.China \\ Email: shenying@mail.ccut.edu.cn
}

Received May, 2013

\begin{abstract}
Energy security is an issue that many countries pay more attention to. Cooperation is a good way to solute it. According to the complex system theory, the regional energy cooperation means a state or process of balance system formed by the interaction and behavior coordination between agents. The features of the regional energy cooperation risk include: uncertainty, potential, fuzziness, diversity, relevance and particularity. And the regional energy cooperation risk can be divided into risk inside the system such as main body ability structure of the risk and main body decision-making risk, and the risk outside the system such as external environment factors and cooperation pattern factors.
\end{abstract}

Keywords: Energy Security; Regional Cooperation; Risk

\section{Introduction}

In the background of economic globalization and integration, with the growing trend of interconnect and interdependent between energy producers and consumers, as characters of International Energy Security, reciprocity, symbiosis and cooperative appear increasingly. It is a trend to carry out cooperation and participate in the international competition to develop the industry of each country. In international energy security cooperation, the economic environment, political environment, management terms are more complicated than in the domestic areas, while there are a great deal of advantages from participating in International Energy Cooperation. There are a lot of risks, which including not only general risk from opportunism, trust mechanisms, but also special risk because Energy as a commodity has the nature of political, economic and diplomatic. Therefore it is an important problem for cooperative behavior agents to strengthen risk prediction and prevention.

According to the complex system theory, the international energy cooperation risk can be divided into risk inside the system and the risk outside the system. The risk inside the system includes main body ability structure of the risk and main body decision-making risk. The risk outside the system includes external environment factors and cooperation pattern factors.

\section{The Analysis of Regional Energy Cooperation Risk}

${ }^{*}$ Corresponding author.

\subsection{Regional Energy Cooperation Risk Concepts and Features}

"Energy cooperation" is still have no clear uniform definition, but the cognition about energy cooperation understanding of target is consistent: The aim of energy cooperation is to ensure energy security, cooperation is a kind of way to keep energy security, the essence of energy cooperation is take cooperation for safety. The concept of energy cooperation is that it is the unity of process and state, to prediction "static" state from the process of "move", and in turn reflects the process of "move" from the process of "static" state. The regional energy cooperation means a state or process of balance system formed by the interaction and behavior coordination between agents. Its connotation is: 1) behavior subject is governments; 2) cooperation method is dialogue and consultation; 3) the scope of cooperation involves the military, security, foreign, ecological and other areas of production consumption process; 4) goal is to achieve a win-win situation.

We can see that the regional energy cooperation is "set by set", it constitutes by the $\mathrm{N}$ ( $\mathrm{N} \geqslant 2$ system elements, and each system elements is a small set. The unbalanced system is a chaotic system, and it is the original form of cooperation. Temporary balance system will become into the unbalanced system because of the changed conditions, and then become the next starting point of the conversion. The final balance system is an ideal state of cooperation, is also the highest state of cooperation, the performance of cooperation is the largest interests of the whole system. 
The regional energy cooperation contains both the balanced and disequilibrium system state and also contains the conversion process from disequilibrium state to balance state. The relationship between the body means the behavior interaction through the affection between each other in the outside world, the result of the interaction is contradictions and conflicts. Behavior coordination refers to the body through coordination behavior including means or measures to solve the contradictions and conflicts, such as pointing to a balanced "cooperation" and back to a balanced "betrayal", the purpose is to realize their own benefit maximization (cooperation benefits decrease the cost of the betrayal or cooperation income minus the betrayal costs). In particular space, when agents showed clear point to balance system behavior coordination, and began to have the organization function, so the cooperation began. The regional energy cooperation risk is due to the system internal and external potential factors, lead to regional energy cooperation deviation "equilibrium" the possibility and degree of state. This concept contains two meanings: one is the probability of imbalance happened; the other is the extent of the imbalance happened.

1) The uncertainty

The uncertainty means whether or not the risk is happening, whenever it occurs and the loss rate are not certain. This uncertainty is more evident in the regional energy cooperation. For example, some risk occur in the cooperation, some risk occur in the cooperation process produces, some occur in the end of cooperation. The state of risk and the influence degree of uncertainty change are random happen.

2) The potential

The potential is the existence of risk in basic form. In addition, the risk can exist in certain conditions as the prerequisite. With the change of external environment, the risk in regional energy cooperation can present different development trend.

3) The fuzziness

The internal and external environment is very complex in the regional energy cooperation. Some information is known, while some other information is unknown. The influence of risk factors is very difficult to quantify .In addition, risk factors can't accurately describe.

4) The diversity

The scope of the regional energy cooperation and energy of the economical, political and diplomatic triple attributes to the diversity of risk. The regional energy cooperation has much risk which includes economic, political and management.

5) The relevance

Risk factors in the regional energy cooperation can relate to each other .In addition, they can influence each other .In addition, a kind of risk factor may cause other risk factors ensued, and even cause the disruption of cooperation .As a result, the influence of cooperation is integrity, such as political friction may bring economical contradiction and environmental protection contradiction, resulting in the risk of management techniques.

6) The particularity

Relative to the general cooperation, energy cooperation risk has its particularity. Energy is often as countries carry out the strategy of points, so the risk of energy cooperation has characteristics of political strategy.

\subsection{The Risk Source of Regional Energy Cooperation}

According to the definition, all the influence of factors which can destroy stable cooperation may result in the occurrence of cooperation risk.

To begin with, from benefits of the conflict, the regional energy cooperation is ultimately behavior between bodies of cooperation, the fundamental purpose of the behavior cooperation is benefits. If actions without expected benefits in the cooperation, it may choose to quit. Each behavior body can hope its own benefits are the largest. At the same time, they can hope to benefits from cooperation that shares the largest piece of. Once the behavior body do not get due reward, other agents from cooperation can get the far more profitable than him, the cooperative initiative will inevitably be hit, as soon as the other opportunities, very likely choose betrayal.

Secondly, the behavior of energy cooperation is spontaneously formed which has individual independence. In addition to contract or agreement, the behavior of energy cooperation is not coercion constraints or control. Agents to continue or not random cooperation, distrust and speculation will be moved cooperation. The characteristics of energy cooperation to cooperation risk is not completely avoided, so the only can do is is how to reduce the occurrence of possibility, cooperation is more likely.

Finally, the external environment of the regional energy cooperation is an important factor [1]. The regional energy cooperation not only considers the economical environment, but also considers the political environment. Cooperation of both sides is whether it helps to promote cooperation on international relations, domestic political environment is stable, policy and economic environment on energy cooperation is to encourage or restrictions.

\section{The Risk of Subject Ability Structure}

In recent years, some scholars study the influence of the ability structure to the regional cooperation. Cui Wei-guo (2004) [2] shows that when the ability is too big between regions, cooperation is almost have no chance. Yang Xian-ming (2005) [3] based on principal component analysis, choose the allocation of resources capacity, the 
transformation of the industrial structure ability, the technical development capability, trade development capacity and opening economy ability and these five indicators to evaluate the ability of structure level, and show the influence of the area ability structure to regional cooperation. Huang Ning (2008) [4] by using the coupling formula of district ability structure, explain two areas where the more similar the total capacity structure index and the bigger the ability structure of the coupling index, the greater likelihood the two areas to develop the economic cooperation. Proof that the two regions structure decides the ability to gain total benefits of cooperation size, the stronger the both part of cooperation ability structure, the greater total benefits the cooperation can achieve, and the part which have strong ability structure may obtain more benefit. These studies showed the main body ability structure decides the regional cooperation scope and cooperation efficiency.

This paper begin with the emphasize of the structure ability of main body, according to the characteristics of the international energy cooperation, Have the evaluation from the following four aspects: the allocation of resources capacity, technical development ability, the trade development ability and the ability to open economic, and get ability structure index through the calculation. This paper discusses the influence of the structure of the country's ability to the region's energy cooperation, "for short, body ability structure of the risk.

\subsection{The Allocation of Resources Capacity}

The index of resources capacity allocation mainly is constituted by the index of level of economic development, investment spending, and financial position of government, the degree of mercerization and allocation efficiency. It includes economy aggregate, population, social total retail sales of consumer goods, the total amount of investment and the level of industrial structure.

\subsection{Trade Development Ability}

Reflect economic extroverted degree, including total import and export, FDI absorbed dose and FDI absorbed dose per GDP.

\subsection{The Economic Open Ability}

Ensure that you return to the 'Els-body-text' style, the style that you will mainly be using for large blocks of text, when you have completed your bulleted list.

\subsection{Technology Development Ability}

Technology development capability index consists of several indicators including technology innovation, the technical transformation, technology absorb. It also In- clude human input proportion, labor productivity and the percentage of $R \& D$ in GDP.

\section{Subject Decision-making Risk}

Behavior subject is the leader and participant of the energy cooperation, with the cooperation's generation and development, behavior between bodies from the start of the isolated affection to each other transformed into contact interaction. Behavior decision-making risk mainly shows the following respects in the game playing.

\subsection{Trust Risk}

Trust is a powerful guarantee to maintain the process of cooperation. Agents lack of mutual trust, which will increase wrong cognition and hostility between each other for cooperation intention, cooperation ability, increase conflict of interests in cooperation on both sides, influencing behavior body's decision-making. At present, psychology, sociology and economics, and other disciplines have relatively common understanding on trust production and the existence conditions, mainly refers to interdependence, communication and continuous contacts [5].

\subsection{Opportunism Risk}

Opportunistic is a form of behavior which pay attention to the interests of the short-term. The behavior body's subjective understanding and psychological anticipation can form different cooperation vision, and have different expectations about the future benefits. When a real income and ideal income have larger divide, the body behavior in the next cooperation may exit. Or in a game, earn temporarily interests, withdraw cooperation. If the actions in the cooperation opportunity in the body pursue socialist, seek temporary interest, and damage the interests of the partner, which will definitely affect the continuous and stable cooperation.

\subsection{Information Asymmetry}

The objective cause of the information asymmetry is that information is processed data, due to data collection staff, technical, the method, the purpose is different, after data processing the information upon which it is unified, and the more the processed process and levels and the errors to the more times amplified, the greater the information distortion. Subjective reason is that different economic individuals get information asymmetry of ability, and at the same time the provider are interested in news keep some important information or distribute some false information, and another on the market there are insider trading which will also lead to both trade information asymmetry. In the process of repeated game, information 
asymmetry often make the body to make the wrong decision behavior, the betrayal of a party in order to avoid suffered losses because of betrayal in the next cooperation.

\section{The External Environment Factors}

The international energy cooperation system's economic environment and the political environment is the main source of external cooperation risk [6]. The Table 1 below shows the international energy cooperation risk environment factors.

\section{Cooperation Pattern Factors}

Cooperation pattern is to point to the energy consumer country realize the energy consumer energy security; take effective cooperation way to solve these problem [7]. According to the historical experience, the international energy cooperation pattern mainly has: the common goal cooperation, share information cooperation and common action cooperation and depend on each other cooperation [8]. The first three cooperation pattern is mainly used for the cooperation between consumer country and the last one is used for the cooperation between producers and consumers.

\subsection{Common Goal Cooperation}

This model only limited target, not set ways and the methods, the elastic is larger. According to their specific countries different measures have been taken, more

Table 1. The international energy cooperation risk environmental factors.

\begin{tabular}{ll}
\hline \multicolumn{1}{c}{$\begin{array}{c}\text { Environmental } \\
\text { risk category }\end{array}$} & \multicolumn{1}{c}{ Risk environmental factors } \\
\hline $\begin{array}{l}\text { Geopolitical } \\
\text { environment }\end{array}$ & geopolitical \\
$\begin{array}{l}\text { International } \\
\text { relations }\end{array}$ & Political relations, economic relations \\
$\begin{array}{l}\text { Economic } \\
\text { environment }\end{array}$ & $\begin{array}{l}\text { Economic level, inflation, and foreign } \\
\text { exchange policy, economic risk }\end{array}$ \\
$\begin{array}{l}\text { Cost environment } \\
\text { Finance and tax } \\
\text { environment }\end{array}$ & $\begin{array}{l}\text { Exploration and development cost, profit } \\
\text { standard, infrastructure, pipe facilities }\end{array}$ \\
$\begin{array}{l}\text { Currency stability, the terms of the contract, } \\
\text { the tax system, the contractor earnings ratio, } \\
\text { and cost recovery limit }\end{array}$ \\
$\begin{array}{l}\text { System } \\
\text { environment }\end{array}$ & $\begin{array}{l}\text { Political stability, political risk, political } \\
\text { system }\end{array}$ \\
\hline $\begin{array}{l}\text { Availability of resources, system stability, } \\
\text { policy available for foreigners, the mining } \\
\text { right, the openness of resources cooperation, } \\
\text { foreign cooperation policy }\end{array}$
\end{tabular}

flexible, so, main body ability structure of the risk and the external environment factors have little influence. The target set by the all countries is consensus. Each country against the wishes of the cooperation is very small, speculative risk is not big. However, this pattern has not the effectiveness of enforcement, and set the common goal of general is long-term, profit is not sure in the long-term, which will affect cooperation faith and the enthusiasm in short term, trust risk and asymmetric information risk may produce during the cooperation. This model is used to solve "long-term supply" problems between consumer countries, set a unity of purpose. As for IEA is oil member in 1985 set 12 guiding principles about oil imports goals and energy policy.

\subsection{Sharing Information Cooperation}

Share information requirements agents to provide timely complete information to each other, can avoid the asymmetric information, to obtain more information from both parties, bring the long-term benefits, the risk of information asymmetry is not big. But, the parties will worry about the truth be understand by the external, thus creating the opportunity and conditions for the competitor or fear that the other party to provide false information and achieve unbalance benefit. So, it's easy to produce the trust risk and speculative risk. Second oil crisis, the IEA expand the member countries to share information cooperation, to the oil market, oil reserves, oil exploration information comprehensive monitoring, with important information released in time, avoid the market price, chaos and irrational decisions. Between member states set up promptly supply and demand in time, long-term supply and long-term needs of the comprehensive information sharing cooperation.

\subsection{Common Action Cooperation}

Common action cooperation pattern is a higher mandatory cooperation pattern, under this pattern the obligation of all parties burden is heavy, the cost of all countries and betrayal is higher, implement it step by step, depending on the behavior of the other countries to decide whether the next step cooperation is going on, this way effectively prevent betrayal behavior occurrence, beneficial to the long-term cooperation. But, this kind of cooperation pattern have the influence of international body ability structure is bigger, it is, the more urgent and mandatory the situation, the notable the ability structure risk. In addition, the cost and benefit from cooperation distribution difficulties, so trust risk and information asymmetry risk is great. IEA internal emergency oil sharing mechanism, IEA about national emergency oil sharing mechanism strategic petroleum reserve's number and the provisions of the common release, about the 
"minimum reserve price" regulation, in energy technology to research and belong to the category of common action contract mode.

\subsection{Mutually Dependent Cooperation}

Mutually dependent cooperation involves only two countries, by domestic situation great influence, if one party at a disadvantage, subject to the other party, cooperation uneven distribution of income, the main body of a large effect on the ability structure. Easy to cause the third party to misunderstanding or the third party conflicts of interest, the external environment is also great risk. So countries will not only take bilateral mutually dependent cooperation secure energy security, and will rely on each other and multilateral cooperation combined.

\section{REFERENCES}

[1] Energy Security, "Managing Risk in a Dynamic Legal and Regulatory Environment," www. World online. Ox- ford University Press, 2004.

[2] W. G. Cui and X. H. Liu, "Regional Economics," Bei Jing: Economic Science Press, 2004.

[3] X. M. Yang and Y. Li, "Study on the Pan Pearl River Region Cooperation Based on the Ability Structure," Social Sciences in Guangdong, Vol. 3, 2005, pp. 38-44.

[4] N. Huang, "Model of Relationship between Ability Structure and Economic Cooperation," Contemporary Economics, Vol. 10, 2008, pp. 108-110.

[5] P. Sztompak, “Trust-A Sociological Theory,” Beijing: Zhonghua Book Company, 2005.

[6] H. Z. An, F. R. Chen and Y. L. Lei, “The Design of Energy Resource International Cooperation Environment Assessment Index System,” Reformation \& Strategy, Vol. 23, No. 11, 2007, pp. 45-49.

[7] O. Noreng, “Oil policy in 1980`s: Pattens of International Cooperation,” New York: McGraw-Hill Book Company, 1978.

[8] Z. Z. Ye, "International Energy Cooperation Model and Strategic Choice of China," Doctoral Dissertation of China Foreign Affairs University, 2005. 